\title{
OSCILLATORY AND ASYMPTOTIC BEHAVIOUR OF SECOND ORDER NEUTRAL DYNAMIC EQUATIONS WITH POSITIVE AND NEGATIVE COEFFICIENTS
}

\section{SAROJ PANIGRAHI AND ERCAN TUNÇ}

Abstract. In this paper, oscillatory and asymptotic properties of solutions of nonlinear second order neutral dynamic equations of the form

$$
\left(r(t)(y(t)+p(t) y(\alpha(t)))^{\Delta}\right)^{\Delta}+q(t) G(y(\beta(t)))-h(t) H(y(\gamma(t)))=0
$$

and

$$
\left(r(t)(y(t)+p(t) y(\alpha(t)))^{\Delta}\right)^{\Delta}+q(t) G(y(\beta(t)))-h(t) H(y(\gamma(t)))=f(t)
$$

are studied under assumptions

$$
\int_{0}^{\infty} \frac{1}{r(t)} \Delta t<\infty \text { and } \int_{0}^{\infty} \frac{1}{r(t)} \Delta t=\infty
$$

for various ranges of $p(t)$, where $\mathbb{T}$ is a time scale with $\sup \mathbb{T}=\infty, t \in\left[t_{0}, \infty\right)_{\mathbb{T}}$, and $t_{0} \geqslant 0$. Examples illustrating the results are included.

Mathematics subject classification (2010): 34C10, 34C15, 34N05.

Keywords and phrases: functional dynamic equations, oscillatory, neutral, time scale, nonlinear, second order, positive and negative coefficients.

\section{REFERENCES}

[1] R. P. Agarwal, M. Bohner, T. Li, C. Zhang, A new approach in the study of oscillatory behaviour of even-order neutral delay differential equations, Appl. Math. Comput. 225 (2013), 787-794.

[2] D. K. Anderson and A. Zafer, Nonlinear oscillation of second order dynamic equations on time scales, Appl. Math. Lett. 22 (2009), 1591-1597.

[3] D. D. Bainov, D.P. Mishev, Oscillation Theorey for Neutral Differential Equation with Delay, Hilger, Bristol, 1991.

[4] M. Bohner, Dynamic Equations on Time Scales, Birkhaüser, 2001.

[5] M. Bohner, A. Peterson, Advances in Dynamic Equations on Time Scale, Birkhaüser, 2002.

[6] L.H. Erbe, Q. Kong, B.G. Zhang, Oscillation Theorey for Functional Differential Equation, Dekker, NewYork, 1995.

[7] I. Gyori, G. Ladas, Oscillation Theorey for Delay Differential Equations with Applications, Oxford Univ. Press, London, 1991.

[8] S. Hilger, Analysis on measure chainis: a unified approach to continuous and discrete calculus, Results Math. 18 (1990), 18-56.

[9] B. Karpuz, J. V. Manojlovic, O. Ocalan, Y. Shoukaku, Oscillaton criteria for a class of second-order neutral delay differential equations, Appl. Math. Comput. 210 (2009). 303-312.

[10] I. Kubiaczyk, S. H. Saker, A. Sikorska-Nowak, Oscillaton criteria for nonlinear neutral functional dynamic equations on time scales, Math. Slovaca. 63 (2013), 263-290.

[11] T. Li, Y. V. Rogovvchenko, Oscillation theorems for second-order nonlinear neutral delay differential equations, Abst. Appl. Anal. 2014 (2014), Article ID 594190, 5pages. 
[12] S. Panigrahi and P.R. Reddy, On oscillatory fourth order nonlinear neutral delay dynamic equations, Comput. Math. Appl. 62 (2011), 4258-4271.

[13] H. Qin, N. Shang, Y. Lu, A note on oscillation criteria of second order nonlinear neutral delay differential equations, Comput. Math. Appl. 56 (2008), 2987-2992.

[14] S. H. Saker and D. O'Regan, New oscillation criteria for second-order neutral dynamic equations on time scales via Ricati substitution, Hiroshima Math. J. 42 (1) (2012), 109-122.

[15] E. Thandapani, V. Piramanantham and S. Pinelas, Oscillation criteria for second-order neutral delay dynamic equations with mixed nonlinearities, Advances in Difference Equations, 2011, Article ID594190, 5pages.

[16] E. Thandapani and V. Piramanantham, Oscillation criteria for second order nonlinear neutral dynamic equations on time scales, Tamkang J. Math. 43 (2012), 109-122.

[17] A. K. Tripathy, Oscillation properties of a class of neutral differential equations with positive and negative coefficients, Fasciculi Mathematici, 45 (2010), 133-155.

[18] A. K. Tripathy, Oscillatory behaviour of a class of nonlinear second order mixed difference equations, Elect. J. Qual. Theory of Diff. Eqs. 48 (2010), 1-19.

[19] Q. Yang, Z. Xu, Oscillation criteria for second order quasilinear neutral delay differential equations on time scales, Comput. Math. Appl. 62 (2011), 3682-3691.

[20] Shao-Yan Zhang and Qi-Ru Wang, Oscillation criteria for second-order nonlinear dynamic equations on time scales, Abstract and Applied Analysis, 2012 (2012), Article ID 743469, 20 pages. 